Western Washington University

Western CEDAR

\title{
Travesía de zorros en la última novela de José María Arguedas, el manuscrito Huarochirí y los cuentos orales de los Andes meridionales
}

Blanca Aranda Gómez García Ph.D

Western Washington University, blanca.aranda@wwu.edu

Follow this and additional works at: https://cedar.wwu.edu/mcl_facpubs

Part of the Latin American Literature Commons

\section{Recommended Citation}

Aranda Gómez García, Blanca Ph.D, "Travesía de zorros en la última novela de José María Arguedas, el manuscrito Huarochirí y los cuentos orales de los Andes meridionales" (2016). Modern \& Classical Languages. 67.

https://cedar.wwu.edu/mcl_facpubs/67 


\section{Travesía de zorros en la última novela de José María Arguedas, el manuscrito Huarochirí y los cuentos orales de los Andes meridionales}

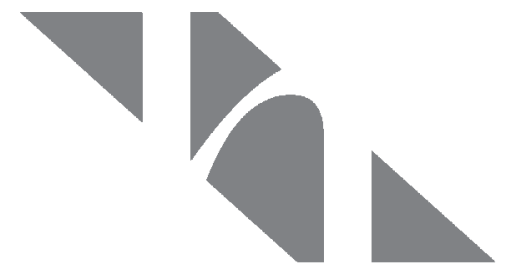

Blanca Aranda Gómez García
Western Washington University

Resumen: A partir del seguimiento del personaje del zorro en la novela El zorro de arriba y el zorro de abajo (1971) de José María Arguedas, este ensayo reconstruye una red intertextual que va más allá del texto escrito conectando la novela con el manuscrito del siglo XVI Dioses y hombres de Huarochirí y con los cuentos orales sobre el zorro en la región de los Andes meridionales. A través de esta lectura comparada, este artículo reconstruye el carácter cómico del personaje del zorro y confirma la relación entre la oralidad y la escritura en la región de los Andes. El seguimiento de esta huella oral-textual revela el carácter fragmentario de la oralidad invitándonos, en el proceso, a continuar la reflexión sobre un intertexto andino que se ve en la necesidad constante de establecer relaciones entre la escritura y la cultura oral en la que esta se enmarca.

Palabras clave: Andes, comical/cómico, Dioses y hombres de Huarochirí, El zorro de arriba y el zorro de abajo, fox/zorro, fragment/fragmento, intertextuality/intertextualidad, José María Arguedas, orality/ oralidad, writing/escritura

$\mathrm{E}$ aspecto cómico del personaje del zorro en la novela El zorro de arriba y el zorro de abajo ${ }^{1}$ del escritor peruano José María Arguedas (1911-69) ha sido pocas veces sujeto de estudio. Dividida en al menos cuatro distintos tipos de texto-relato, diarios, ensayo y carta-la obra invita, desde su aspecto de contenido, al análisis de temas como la pobreza, la discriminación, las diferencias de clase, la explotación, la migración, la identidad, la producción literaria latinoamericana, el suicidio y la sexualidad. Dentro de este marco temático los trabajos de Fergus Mitchell Jr., “The Foxes in Arguedas's Last Novel” (1978), y Martin Lienhard, Cultura andina y forma novelesca (1981), son aproximaciones pioneras respecto de los aspectos cómicos del personaje del zorro. Retomando ambas propuestas, este estudio lleva adelante un análisis que no solo nos obliga a reconstruir su relación intertextual con el manuscrito quechua Dioses y hombres de Huarochirí, sino que además nos invita a salir del texto escrito a la práctica oral de contar cuentos sobre el zorro en los Andes. Este ejercicio de reconstrucción, en el que el personaje del zorro es un fragmento común, destaca la importancia de lo fragmentario en el sistema oral presente en los cuentos orales, el manuscrito y en la estructura formal de Los zorros.

La primera vez que se habla del zorro en la novela de Arguedas se da en el Primer Diario, cuando el narrador recuerda el modo en el que Doña Carmen Taripha, de Maranganí en Cuzco, contaba cuentos al cura para quien trabajaba. En esta descripción, el narrador apunta que en los cuentos en los que el zorro era personaje, este era representado entre "chistoso y cruel" (14). La referencia a los cuentos de Carmen Taripha nos introduce en la relación entre la oralidad y la escritura desde el inicio de la novela, al mismo tiempo que nos brinda la primera descripción de nuestro personaje destacando su personalidad cómica. Después de esta referencia, el zorro aparecerá en la novela desdoblado en "el zorro de arriba y el zorro de abajo", en dos conversaciones aisladas, como Diego el visitante, en el capítulo 3, y como diversos sujetos misteriosos, dispersos a lo largo del relato. 
Cuando el zorro aparece como "el zorro de arriba y el zorro de abajo", la conversación que ambos sostienen aborda aspectos autobiográficos y reflexiones sobre temas como la palabra y el canto. Ambas intervenciones son acompañadas, siguiendo el estudio de Lienhard en Cultura andina y forma novelesca, por "símbolos mágico-poéticos" propios de la cultura andina. Si bien la selección de temas y el cuidado con el que Arguedas introduce en la novela estos símbolos invitan a explorar el carácter serio del intercambio entre los zorros; las esporádicas risas del zorro, "ji, ji, ji ..." (23), y la directa relación intertextual con el manuscrito Dioses y hombres de Huarochirí, de donde Arguedas sacará el personaje del zorro desdoblado en "el zorro de arriba y el zorro de abajo", obligan al lector a salir de la matriz textual de la novela hacia la matriz social del texto en la que el zorro es el personaje cómico por excelencia.

La visita que Diego, el zorro, hizo al gerente de la compañía pesquera Nautilus Fishing de Chimbote, don Ángel Rincón Jaramillo, proporciona aún más información sobre nuestro personaje. Descrito como joven y delgado, de piernas cortas, manos estrechas, amplia boca y ojos que parecen brillar incluso cuando están cerrados, el zorro, con traje de chaleco y sombrero, se presenta aquí humanizado. No obstante se trata de un capítulo concentrado en el personaje del zorro, este está escrito de tal manera que no da certeza alguna respecto de la identidad del mismo. En un ejercicio de reconstrucción, el lector se ve obligado a detenerse en las descripciones de Diego, repartidas a lo largo del capítulo, en las múltiples risas, vertidas en medio de los diálogos, y en los momentos de danza, que el narrador describe como "Una alegría musical . . . cayendo a la arena en cascadas más poderosas y felices que las cataratas de los ríos y torrenteras andinas" (122). La reconstrucción del personaje del zorro a lo largo del capítulo 3 no solo nos confronta con una estructura fragmentada, sino que además nos sumerge en el terreno de lo ambiguo, reforzando la necesidad de generar sentido analizando metáforas como "la alegría musical" y palabras afines a lo cómico como "alegría" y "felices".

La visita de Diego al "Gato Negro", uno de los burdeles de Chimbote en el que baila "La Caprichosa", desnudista que "entusiasma a cojos macos y viejos" (124), incrementa la tensión cómica. La narración de uno de los pasajes más eróticos del texto-la descripción de cómo el Tarta, con rasgos de zorro en ese momento, besa el sexo de la bailarina en el escenario-nos deja ver al zorro en su calidad de pícaro y seductor, al mismo tiempo que enmarca al personaje dentro de la tradición oral a la que pertenece y en la cual se lo representa como un personaje embustero, pícaro, farsante y seductor, todas características propiamente cómicas.

En una lectura comparada entre el personaje del zorro y el danzaq de tijeras, artista cómico de las fiestas andinas en el Perú, Martin Lienhard, en Cultura andina y forma novelesca, lleva adelante un exhaustivo análisis del Capítulo Tres de la novela en el cual establece que el danzante baila en competición con otro y propone que en este capítulo Diego compite con Ángel Rincón. El que Lienhard haya reparado en el aspecto cómico de la novela y el que se haya detenido en la necesidad de estudiarlo en relación con la cultura oral a la que pertenece es un aporte fundamental. Dicho esto, si bien puede haber razones para sostener la comparación entre los zorros, lo cómico y la danza, hay intertextos más próximos que el que trabajó este crítico. Destaca como referencia inmediata el manuscrito Dioses y hombres de Huarochirí, seguido por los cuentos orales sobre el zorro en la región de los Andes.

La ambigüedad que rodea la aparición de un personaje desdoblado en dos y la presencia de un visitante absolutamente fuera de lo común en el Capítulo Tres se potencia con las constantes apariciones de personajes con rasgos de zorro en el resto de la novela. Sus apariciones aisladas nos dejan ver al zorro "haciendo zig-zags" (169) por el arenal en el Capítulo Cuatro, "como joven de rostro alargado" (218) en la Segunda Parte del libro, y en una reaparición como Diego haciendo "vibrar sus piernas abiertas y dobladas en desigual ángulo" (239) justo antes del Último Diario. El zorro, como personaje fragmentado, está en total correspondencia con la ambigüedad que como bien explica Octavio Paz está en directa relación con el género de la novela y con el humor. ${ }^{2}$ A través del personaje del zorro, Arguedas nos introduce en el ejercicio de reconstruir 
fragmentos y, de la mano de la ambigüedad, nos presenta un personaje que en cada una de sus apariciones nos invita a seguir su huella más allá de la novela, adentrándonos en la cultura oral a la que pertenece.

\section{De la reconocida disposición intertextual hacia los mitos prehispánicos al análisis comparado de un personaje cómico}

El manuscrito quechua Runa Yndio Niscap Machoncuna (siglo XVI), conocido bajo el título Dioses y hombres de Huarochirí, constituye la relación intertextual más próxima a Los zorros de Arguedas. Quienes se han dedicado al estudio de la relación entre este manuscrito y la última novela de Arguedas analizan temas como la migración, los personajes míticos, el lenguaje y la presencia del zorro en ambas obras. ${ }^{3}$ Resulta notable que si bien la relación intertextual entre la novela y los mitos prehispánicos registrados en el manuscrito ha sido ampliamente reconocida, los trabajos de investigación que se concentran en este tema se dedican de manera exclusiva al estudio del Capítulo Cinco del manuscrito, al ser este el capítulo del que Arguedas retomará el personaje del zorro desdoblado en "el zorro de arriba y el zorro de abajo". Un seguimiento del personaje del zorro en la totalidad del manuscrito-capítulos 2, 3, 5 y 6 específicamenteposibilita su caracterización como personaje cómico, al mismo tiempo que nos regresa a la actividad de conectar fragmentos y nos invita a salir del texto al contexto de la cultura oral en la que se enmarca este texto. ${ }^{4}$

El capítulo 5 narra la historia de Huatyacuri. Se trata de un mendigo que caminando entre Uracocha y Sieneguilla escucha la conversación de dos zorros. El zorro de la parte alta comparte que el poderoso señor de arriba Tamtañanca se encuentra enfermo a causa de la infidelidad de su esposa. El zorro de la parte baja, por su parte, revela que la hija de un importante jefe "muere por [tener contacto] con un sexo viril" (37). El capítulo continúa relatando la manera en la que Huatyacuri se convierte en señor utilizando la información brindada por los zorros. Más adelante, en el mismo capítulo, el zorro reaparece como víctima de un engaño, planeado por Huatyacuri y su padre Pariacaca, en el que pierde su porongo, jarra pequeña, y su tinya, tamborcillo.

Si bien compartimos la perspectiva de Raúl Bueno, según la cual "los dos zorros se encontraron en el cerro Latausaco de Huarochirí para intercambiar información conflictiva, que en ese entonces era del orden de la sexualidad femenina inaceptable" (18), es importante destacar que a partir de un ejercicio de degradación ${ }^{5}$ se hacen próximos ambos personajes creando un espacio para la risa. ${ }^{6}$ Así, si bien se trata de dos narradores omniscientes, valiosos en su calidad de conocedores absolutos, el intercambio que ambos sostienen, sobre la vida sexual de estas dos mujeres, no solo reduce su conocimiento, sino que degrada el valor mismo del intercambio y, por lo tanto, del encuentro. La degradación continúa cuando se nos narra la manera en la que el zorro fue engañado y perdió sus objetos.

Es en el capítulo 2 en el que vemos por primera vez al zorro como personaje dentro del manuscrito. El relato narra la historia del dios Cuniraya Viracocha, quien toma la apariencia de un hombre muy pobre y se dedica a vagar por los pueblos. En medio de su recorrido engendra un hijo y cuando Cavillaca, la madre, descubre quién es el padre, muy disgustada toma a su hijo y corre en dirección al mar. El dios, que para este momento vestía sus ropas de oro, sale en pos de la mujer encontrando en el camino a varios animales a quienes les pregunta si acaso la habían visto. De acuerdo a las respuestas positivas y alentadoras o negativas y desalentadoras, confiere dones o maldiciones a los informantes. El zorro responde que Cavillaca está muy lejos y que no la encontrará. Cuniraya Viracocha, entonces, maldice al zorro diciéndole: "aun cuando camines lejos de los hombres, que han de odiarte, te perseguirán; dirán: 'ese zorro infeliz', y no se conformarán con matarte; para su placer, pisarán tu cuero, lo maltratarán” (29). Se puede ver que desde el inicio del manuscrito, el zorro se nos presenta como uno de los animales andinos y, dentro de este grupo, como uno que no recibirá favor alguno del dios Curinaya Viracocha. 
Su actitud pesimista lo define y al mismo tiempo que nos conmueve su sinceridad, nos invita a reír su mala fortuna.

El capítulo 3 se concentra en la narración de cómo en tiempos muy antiguos el mundo estaba en peligro de desaparecer. Cuenta el mito que una llama le dijo a un hombre que en cinco días el gran lago llegaría y todo acabaría. Entonces, para salvarse, el hombre, su familia y los animales suben hasta la punta de la montaña Huillcacoto, desde donde ven caer el agua en cataratas. El agua sube inundándolo todo excepto la punta del cerro en la que todos se habían resguardado y solo logra "tocar el extremo del rabo del zorro" (33), mojándolo y dejándolo como lo conocemos hoy: ennegrecido. La historia concluye relatando cómo fue que, cumplidos los cinco días, el agua descendió y el mar se retiró, dejando como únicos sobrevivientes a quienes habían buscado refugio en la montaña. El aspecto cómico es más claro en este mito. Así, mientras que todos los que se refugian en la montaña quedan ilesos, solo el zorro sufre la desventura de meter la cola en el agua y si bien se salva, no logra salir completamente ileso.

La última vez que vemos al zorro como personaje en Dioses y hombres de Huarochirí es en el capítulo 6. Este relata la manera en la que Pariacaca empezó a buscar a su enemigo Huallallo Carhuincho, cómo fue que hizo crecer las aguas obligando a las personas a bajar a la zona caliente de Yancacuna y cómo llevó agua al pueblo de Cupara. Es en esta última parte de la historia en la que se nos cuenta que en aquel tiempo vivía en ese pueblo una mujer muy hermosa llamada Chuquisuso. Pariacaca, al ver que ella lloraba porque no tenía agua para sus cultivos, le ofrece ayuda a cambio de poder dormir con ella. Chuquicuso acepta, pero establece que lo haría después de obtener el agua. Entonces el dios hizo venir mucha agua y la mujer regó no solo sus campos, sino todos los de la región. Cuando Pariacaca quiso que la mujer cumpliera con su parte del acuerdo, esta le hizo prometer además que él convertiría todos los campos en tierras con riego. Pariacaca aceptó, sabiendo que para lograr ese objetivo tendría que convertir un acueducto en una acequia. Necesitaba la ayuda de los animales y contó con la colaboración de pumas, serpientes, pájaros y del zorro, quien además se ofreció de guía para llevar adelante la obra. Iba guiando el zorro al resto de los animales, cuando, en el momento en el que todos estaban en la cima del cerro, se asustó por el vuelo de una perdiz. Saltó gritando y cayó rodando cuesta abajo. Siendo que todos los animales debían seguirlo, la acequia se construyó por debajo de donde tenía que ser construida. La narración finaliza estableciendo que "aún se ve muy claro dónde cayó el zorro; el agua baja por allí mismo" (47).

Este es uno de los mitos que de manera más clara nos deja ver las particularidades cómicas del zorro. Así, comprobamos que, a pesar de tener buenas intenciones, su personalidad no lo ayuda. Resulta cómico que, después de haber tenido que argumentar para lograr ser elegido guía, falle. El efecto es aún más risible si tenemos presente que el motivo por el que el zorro se asusta no es un evento mayor, sino uno muy cotidiano y sumamente inofensivo: el vuelo de una perdiz. Si, además, tenemos en cuenta que se trataba de un trabajo muy importante por haber sido encargo de un dios, resulta todavía más cómico el error del zorro, error, que hasta el día de hoy se puede ver en el diseño mismo del acueducto y del que se reirá todavía por muchas generaciones.

El manuscrito Dioses y hombres de Huarochirí confirma las características cómicas del zorro regresándonos la imagen de un animal que si bien conoce el mundo de arriba y el de abajo, es constantemente degradado. Hábil, a veces gana como cuando consigue salvarse de la inundación y a veces pierde como cuando es engañado, cuando es maldecido por un dios y cuando no logra llevar a buen fin una obra. La representación del zorro como aquel personaje condenado a perder y destinado a sobrevivir nos invita a salir del texto escrito al contexto de la tradición oral en la que se enmarcan los dos textos hasta aquí analizados. Los cuentos orales sobre el zorro contribuyen a la caracterización de nuestro personaje, al mismo tiempo que forman parte de este ejercicio de reconstrucción de fragmentos que han sabido convivir entre la oralidad y la escritura. 


\section{Del contexto textual al paradigma de la tradición oral}

Retomando el aporte que hizo Flores Ochoa sobre la mitología de los pastores en la región de los Andes meridionales, Denise Arnold, Domingo Jiménez y Juan de Dios Yapita establecen, en su estudio Hacia un orden andino de las cosas, que los cuentos orales en esta región se dividen en dos géneros: Uywa, relatos sobre los animales domesticados, y Sallqa parla, relatos sobre los animales salvajes. Sobre los cuentos que tienen como personaje al zorro, se nos dice:

Como sallqa parla o siñjtäru, estos cuentos describen inevitablemente al farsante tímido, al sallqa por excelencia: el zorro, como la bestia silvestre arquetípica. Sallqa expresa perfectamente los diversos aspectos de su carácter salvaje e incontrolable, su timidez, su habilidad como embustero y atrapado, para sobrevivir mediante la bendición de su buena suerte excepcional ... El género entero de cuentos acerca de las bestias silvestres es llamado por los Qaqas simplemente sallqa parla, o liq'uchi parla: "habla del zorro". (178)

Arnold explica además que la expresión sallqa parla tiene relación con el verbo aymara sallqaña, que en español se traduce como engañar, y que esta mantiene el mismo sentido en la región quechua de Ayacucho en el Perú. La recopilación de los cuentos sobre el zorro, a la vez que nos permite seguir conociendo a nuestro personaje, contribuye con el trabajo de delimitación de la región andina a partir de sus semejanzas y sus especificidades.

Después de consultar Madre melliza y sus crías, de Arnold y Yapita; Aldeas sumergidas, de Efraín Morote; Mitos, leyendas y cuentos peruanos, de Arguedas e Izquierdo; y la edición dirigida por Wilfredo Kapsoli de El cóndor y el zorro, de Max Uhle; se pueden confirmar varias de las características dadas para el personaje del zorro, tanto en el manuscrito Dioses y hombres de Huarochirí, como en la novela Los zorros. Dentro de los diversos cuentos que tienen al zorro como personaje, aquel que narra su viaje al cielo presenta la mayor cantidad de características asociadas con este animal. En una lectura comparada de los cuentos "El zorro y la araña" y "El zorro y el loro", documentados en Madre melliza y sus crías, ${ }^{7}$ y doce versiones del cuento "El viaje al cielo", registradas en Aldeas sumergidas, ${ }^{8}$ podemos reconstruir un relato que nos deja conocer mejor el personaje del zorro andino.

"El viaje al cielo" presenta los siguientes núcleos narrativos: el zorro quiere asistir a un banquete en el cielo, pide a otro animal que lo transporte, logra su objetivo utilizando un habla familiar, carismático y seductor. Una vez en el cielo, siguiendo el texto de Morote: "El zorro comete mil fechorías; roba, se entromete, molesta", "pelea con un cóndor pequeño por un pedazo de carne", "come, sin permiso", "bebe chicha" (62), "se mete a la cocina, se mete debajo de la mesa en pos de huesos y al encontrarlos y quererlos quitar, pelea con los perros del cielo, tumba la mesa, mancha con el vino 'tinto' las blancas bufandas de los comensales y, absolutamente borracho, se niega a regresar a la tierra" (63). En todos los casos, el zorro es abandonado y se ve en la necesidad de utilizar una cuerda para regresar a la tierra. En medio del camino, el zorro, todavía borracho, encuentra unos loritos. Estos se enfadan con el zorro, porque este no hace más que burlarse de ellos, y cortan la cuerda por la que está bajando. En medio de su caída, el zorro pide ayuda. Muchas veces solicita que extiendan una frazada o que la araña teja una tela que lo salve, pero el destino del zorro es caer. Dependiendo de las distintas versiones: muchas veces los animales no acuden al auxilio del zorro pues piensan que se trata de otra de sus picardías; otras veces el ratón, su archienemigo, en lugar de extender una frazada, pone piedras puntiagudas; o, en caso de tener la suerte de que la araña decida ayudarlo y teja una tela para salvarlo, el zorro, por falta de coordinación, cae fuera de la misma. El zorro revienta en múltiples productos agrícolas propios a esta región andina.

La tradición oral confirma la información que tanto el manuscrito como la novela nos brindan sobre el zorro. Lo vemos transitar espacios opuestos, un animal de la tierra que visita el cielo, reencontramos su personalidad de pícaro, obtiene favores haciendo uso de su personalidad 
carismática, y nos vemos transportados al universo de lo cómico en el que incluso el desenlace trágico del zorro es risible. Ya sea que sobreviva la caída o que en el impacto explote en diversos productos alimenticios, el zorro permanece y con él sus historias.

Sobre el zorro andino Tristan Platt nos explica, en "Symétries en miroir le concept de yanantin chez les Macha de Bolivie" que, en efecto, el animal zorro es considerado un mediador entre las montañas y los valles en la región de los Andes. Así, "si se ve que el zorro (atuj) se dirige hacia las alturas en septiembre (época de siembra), se piensa que el año será fecundo en la puna; pero, si se lo ve descender, el año será bueno en el valle" (1085 mi traducción del francés). El tránsito del zorro revela ser un fragmento de información respecto de la producción agrícola en las comunidades que los cuentos orales sobre el zorro, a través del relato del viaje del zorro de la tierra al cielo y su explosión en distintos productos, habrían logrado mantener.

Así mismo, si retomamos el estudio de Frank Salomon en "How the huacas were", podemos confirmar que el manuscrito Dioses y hombres de Huarochirí documenta la relación histórica de invasiones constantes entre los Yauyos serranos y los Yunca vallunos. Se trataba de una lucha basada en la necesidad mutua de manejar el territorio de forma vertical, de manera de poder utilizar las tierras bajas cultivables del valle y tener acceso al curso de las aguas provenientes de las montañas que riegan esos mismos terrenos. ${ }^{9}$ La aparición de los zorros en el capítulo 5 sería la referencia más clara a la capacidad de tránsito del zorro y a la dinámica del movimiento migratorio entre ambas zonas.

Para el caso de Los zorros, la crítica sobre la novela ha visto el tema del tránsito entre arriba y abajo de diferentes formas que en este estudio clasificamos en tres grandes grupos: aquellos que ven esa oposición como la posibilidad de narrar sobre ambos mundos o ver en estos otros opuestos que analizar para anularlos o destacarlos; aquellos que exploran la importancia del tránsito en la figura del migrante deteniéndose en el sentido social de la migración entre la sierra y la costa; y los que entienden la oposición como posibilidad de una narración "mágico realista" o exploración del aspecto mítico. ${ }^{10} \mathrm{Si}$ bien la contextualización de la división entre arriba y abajo deviene en todas estas propuestas en una conciencia de la presencia de la cultura oral en la novela, se debe destacar que la aparición de un zorro de arriba y otro de abajo, desde un análisis que privilegia la intervención de un fragmento oral en la novela, brinda la posibilidad de conectar de manera inmediata tiempos históricos y regiones geográficas. Al mismo tiempo, el tránsito del zorro nos invita a reflexionar sobre aspectos que escapan a los ejes temporal y espacial como son el contacto y el conflicto cultural. Solo a través del fragmento, elemento propio a lo oral, puede ser probable lo imposible: la convergencia de tiempos y espacios, la reconstrucción, a partir de huellas repartidas, de un sistema en constante cambio. El tránsito del zorro, sujeto serrano/costeño, campesino/obrero, seductor de pastoras/amante de prostitutas, no solo nos brinda una perspectiva nueva sobre este personaje, sino que además nos ayuda a descubrir y formular características de lo que conocemos como oralidad. La novela publicada en 1971, el manuscrito del siglo XVI y la tradición oral de ayer y de hoy, se conectan a través de fragmentos comunes que documentan y resisten el paso del tiempo.

\section{A partir de un fragmento: La actividad infinita de semantizar}

El seguimiento del zorro en la novela, el manuscrito y los cuentos orales nos invita a llevar adelante un ejercicio constante de semantización. Lo vemos transitando espacios opuestos, utilizando su personalidad carismática para obtener beneficios, desempeñando su papel de pícaro, y sobreviviendo peligrosos obstáculos. A través de la reconstrucción de la huella fragmentada de este personaje confirmamos su personalidad cómica, a la vez que revelamos la importancia de lo fragmentario para la oralidad y para la convivencia de la oralidad y la escritura en la región de los Andes.

Eduardo Huarag, en "Manifestaciones de la oralidad como sistema de expresión literaria y mítica en algunos relatos de Arguedas", apunta que no se debe confundir la oralidad discursiva 
con la oralidad como sistema de cultura. La oralidad discursiva se manifiesta a través de un texto literario que utiliza un tipo de escritura en el relato y otro en el habla oral de los personajes en los diálogos. La oralidad como sistema de cultura "comprende las manifestaciones, costumbres y modos de pensar de un grupo determinado" (178), de manera de ir más allá de las particularidades discursivas saliendo del intercambio oral a la cultura en la que se da el mismo y a una suerte de sistema de pensamiento propiamente oral.

La exploración de las características de lo que se conoce como oralidad ha sido tema de investigación de distintas ramas de estudio. ${ }^{11}$ Los trabajos de Denise Arnold, Río de vellón, río de canto y El rincón de las cabezas, Margot Beyersdorff y Dedenbach-Salazar, Andean Oral Traditions, Rosaleen Howard Malverde, "Storytelling Strategies", Eduardo Huarag, "Manifestaciones de la oralidad", y Nina Gerassi-Navarro, "Huarochirí recordando las voces del pasado en los mitos de creación", nos ayudan a definir algunas de las características de la oralidad para la región de los Andes. El aporte de estas propuestas es invaluable y si bien cada una de ellas desarrolla algunas características más que otras, casi en todos los casos utilizando distintas denominaciones para las mismas características, todas ellas contribuyen a una mejor comprensión de lo que significa ser una cultura oral y a la valoración de la misma. De una lectura comparada de estas propuestas desprendemos cinco características del sistema oral y, en busca de una mejor comprensión, las comparamos con cinco características propias al sistema escrito.

Mientras que el sistema escrito debe ceñirse al sintagma fijo que impone un orden en la construcción del discurso, en la tradición oral lo importante es la conservación de los elementos básicos de la trama: fragmentos. En el sistema escrito, la conservación del texto sin alteración de sus partes o del orden en el que estas aparecen tiene un gran valor; la oralidad, por el contrario, da valor a la calidad de los cambios en la nueva variante del relato. El texto escrito, en un afán por construir sentido, nos remite siempre hacia adelante para poder tener una idea del todo, mientras que el relato dentro de la tradición oral nos proyecta tanto hacia las versiones anteriores del relato (atrás) como a la gestación de la variante nueva (adelante), desde el inicio mismo de la historia. En el sistema escrito la idea de totalidad se sustenta en la materialidad misma del documento, mientras que en la tradición oral la idea de totalidad solo es posible a través de la comprensión de la necesidad constante de resemantizar los fragmentos. Finalmente, mientras que en el sistema escrito el texto es una entidad independiente del lector y el escritor, en la tradición oral, el emisor, el relato y el receptor forman parte de un cuerpo indivisible destinado a preservar ${ }^{12}$ la memoria colectiva en un marco común de referencia.

Las características hasta aquí apuntadas nos ayudan a ver la tradición oral y el sistema escrito como entidades completamente distintas. Al mismo tiempo se puede comprobar, a través de la reconstrucción de un fragmento como es el personaje del zorro, que para el caso de las culturas andinas se trata de dos universos conectados por siglos de convivencia. La salida del texto escrito al contexto oral propone un intertexto andino capaz de albergar textos escritos, textualidades alternativas y prácticas textuales. El tránsito del zorro es también la travesía del intertexto y de una oralidad que permanece en múltiples transformaciones.

\section{AGRADECIMIENTOS}

Doy las gracias a mi abuelo, Ángel Gómez García, por haberme abierto la puerta de la oralidad en los Andes. Agradezco igualmente el apoyo que me brindó Western Washington University a través de la beca New Faculty Summer Research Grant.

\section{NOTAS}

${ }^{1}$ A partir de ahora y a lo largo de este artículo siempre que se haga referencia a la novela El zorro de arriba y el zorro de abajo utilizaremos el título abreviado: Los zorros, denominación familiar que utilizó Arguedas para hablar de esta obra. La edición utilizada para llevar adelante el análisis de la novela es la de la Colección Archivos (1990). 
${ }^{2}$ Para una mejor comprensión de la relación entre la ambigüedad, la novela y el humor, confrontar el capítulo "La ambigüedad de la novela" en El arco y la Lira de Paz.

${ }^{3}$ Para el tema de migración consultar los estudios de Cornejo Polar ("Tradición migrante") y de Ortega. Sobre los personajes míticos consultar las propuestas de Arroyo y de Cornejo Polar, "El zorro de arriba y el zorro de abajo palabra y realidad”. Para el tema del lenguaje consultar Castro-Klaren, Gómez Mango, y Rowe. Sobre el personaje del zorro consultar los estudios de Lienhard, Mitchell y Westphalen.

${ }^{4}$ En el estudio introductorio a la traducción del manuscrito, Arguedas establece que "El estilo del manuscrito es predominantemente oral” (10). Urioste explica que el manuscrito es una colección editada de varias tradiciones orales de la región de Huarochirí (véase Hijos de Pariya Qaqa). Gerassi-Navarro propone que se trata de una recopilación de testimonios orales de los pobladores de Yunca, Checa y Concha y que "La diversidad de comunidades, cada una con su historia particular, explicaría la pluralidad de voces, digresiones, contradicciones y diferencias lingüísticas que recorren el texto" (98-99). Finalmente, Ortiz Rescaniere confirma la intervención de la oralidad en el manuscrito cuando en un estudio comparado, Huarochirí cuatrocientos años después, afirma que la gente de la región de Huarochirí ha sabido conservar sus tradiciones míticas sin la intervención del manuscrito.

${ }^{5}$ En Filosofía de la risa y el llanto, Stern explica que las entidades que nos hacen reír o llorar no son racionales sino emotivas, que lo cómico no existe fuera de aquello que es propiamente humano al ser este el único portador de todos los valores y que el efecto cómico es resultado de la degradación de los mismos. Las constantes degradaciones del personaje, del zorro en este caso específico, conducen, siguiendo la propuesta de Stern, a la obtención del efecto cómico.

${ }^{6} \mathrm{El}$ acercamiento filosófico social de Bajtín propone que la risa destruye toda distancia jerárquica, que una figura alejada no puede ser cómica, y que solo la proximidad puede convertir algo en materia risible.

7 "El zorro y la araña" y "El zorro y el loro" pertenecen a la región andina boliviana. El primero es de la comunidad Chukiñapi del cantón Kalaki, en Santiago de Huata provincia Humasuyos, departamento de La Paz. El segundo de la comunidad Cóndor Pampa, ayllu Aymaya, provincia Chayanta, norte de Potosí.

${ }^{8}$ Las doce versiones con sus respectivas variantes del cuento "El viaje al cielo" provienen de las regiones Q'ero en la cordillera oriental de los Andes y Qochas en el distrito de San Miguel, provincia la Mar, departamento de Ayacucho, Perú.

${ }^{9}$ La división entre Yauyos serranos y Yunca vallunos, siguiendo a Urton, se complica aún más si se tiene en cuenta que cada uno de estos grupos está compuesto por varias comunidades que a su vez se subdividen entre la parte de arriba y la parte de abajo.

${ }^{10}$ Dentro del primer grupo destacan los textos de Aibar, Arroyo, Forgues, Lienhard, Mitchell y Ortega. Para el segundo, "Tradición migrante" de Cornejo Polar y "Del mito al testimonio" de Westphalen. Forman parte del tercer grupo: "José María Arguedas o la palabra herida" de Fell y "Arguedas o el creador visceral" de Ratto. Los estudios previamente mencionados no son exclusivos y en todos los casos retoman aspectos de otros grupos. La división que aquí se presenta responde a una voluntad de aproximación a partir de una lectura que se concentra en el personaje del zorro como fragmento dentro de una cultura oral.

${ }^{11}$ Para llevar adelante un estudio general sobre la oralidad revisar el libro de Ong.

${ }^{12}$ La preservación de los fragmentos se lleva adelante en muchos casos a través de la teatralidad, generalmente denominada como performance. Preferimos utilizar el término teatralidad y no performance por ser este, siguiendo la propuesta de Vargas-Salgado, un concepto culturalmente flexible que permite entender el proceso de recuperación de la memoria.

\section{OBRAS CITADAS}

Aibar Ray, Elena. Identidad y resistencia cultural en las obras de José María Arguedas. Lima: Fondo Editorial de la Pontificia Universidad Católica del Perú, 1992. Impreso.

Arguedas, José María. El zorro de arriba y el zorro de abajo. Ed. Eve-Marie Fell. Madrid: Archivos, 1990. Impreso.

Arguedas, José María, y Francisco Izquierdo Ríos, eds. Mitos, leyendas y cuentos peruanos. Lima: Casa de la cultura del Perú, 1970. Impreso.

Arnold, Denise Y. Río de vellón, río de canto, Cantar a los animales, una poética andina de la creación. La Paz: ILCA/Hisbol, 1998. Impreso.

Arnold, Denise Y., y Juan de Dios Yapita. El rincón de las cabezas: Luchas textuales, educación y tierras en los Andes. La Paz: Facultad de Humanidades y Ciencias de la Educación UMSA e ILCA, 2005. Impreso.

Arnold, Denise Y., y Juan de Dios Yapita, eds. Madre melliza y sus crías, Ispall mama wawampi, Antología de la papa. La Paz: Hisbol/ILCA, 1996. Impreso. 
Arnold, Denise Y., Domingo A. Jiménez, y Juan de Dios Yapita. Hacia un orden andino de las cosas, Tres pistas de los Andes meridionales. La Paz: Hisbol/ILCA, 1992. Impreso.

Arroyo, Eduardo. "Los zorros: Modernidad urbana y mito andino". Zorros a fin del milenio: Actas y ensayos del Seminario sobre la última novela de José María Arguedas. Ed. Wilfredo Kapsoli. Lima: Universidad Ricardo Palma, 2004. Impreso. 13-40.

Bajtín, Mijaíl. La cultura popular en la Edad Media y en el Renacimiento: El contexto de François Rabelais. Madrid: Alianza, 1998. Impreso.

Beyersdorff, Margot, y Sabine Dedenbach-Salazar Sáenz, eds. Andean Oral Traditions: Discourse and Literature / Tradiciones orales andinas: Discurso y literatura. Bonn: Holos, 1994. Impreso.

Bueno, Raúl. "Poética narrativa y traducción cultural en José María Arguedas". Revista de crítica literaria latinoamericana 38.75 (2012): 11-25. Impreso.

Castro-Klaren, Sara. "Como chancho cuando piensa: El afecto cognitivo en Arguedas y el con-vertir animal". Revista canadiense de estudios hispánicos 26.1-2 (2001-02): 25-39. JSTOR. Web. 10 oct. 2013.

Cornejo Polar, Antonio. "Tradición migrante e intertextualidad multicultural: El caso de Arguedas". Zorros a fin del milenio: Actas y ensayos del Seminario sobre la última novela de José María Arguedas. Ed. Wilfredo Kapsoli. Lima: Universidad Ricardo Palma, 2004. 41-52. Impreso.

. "El zorro de arriba y el zorro de abajo palabra y realidad". Los hervores de Chimbote en los zorros de arriba y los zorros de abajo de José María Arguedas. Ed. Jaime Gumán Aranda. Lima: Río Santa, 2006. 17-76. Impreso.

Dioses y hombres de Huarochirí. Trad. José María Arguedas. México: Siglo XXI, 1975. Impreso.

Fell, Eve-Marie. "Introducción". El zorro de arriba y el zorro de abajo. Ed. Eve-Marie Fell. Madrid: Archivos, 1990. xxi-xxvii. Impreso.

Forgues, Roland. "Estructura y significado de El zorro de arriba y el zorro de abajo". Zorros a fin del milenio: Actas y ensayos del seminario sobre la última novela de José María Arguedas. Ed. Wilfredo Kapsoli. Lima: Universidad Ricardo Palma, 2004. 53-65. Impreso.

Gerassi-Navarro, Nina. "Huarochirí recordando las voces del pasado en los mitos de creación". Revista iberoamericana 61.170-71 (1995): 95-105. Impreso.

Gómez Mango, Edmundo. "Todas las lenguas: Vida y muerte de la escritura en Los zorros de J. M. Arguedas". El zorro de arriba y el zorro de abajo. Ed. Eve-Marie Fell. Madrid: Archivos, 1990. 360-68. Impreso.

Guzmán Aranda, Jaime, ed. Los hervores de Chimbote en los zorros de arriba y los zorros de debajo de José María Arguedas. Lima: Río Santa, 2006. Impreso.

Howard-Malverde, Rosaleen. "Storytelling Strategies in Quechua Narrative Performance". A View through and Andean Kaleidoskope: The Dynamics of Interpretation. 1988. Impreso.

Huarag, Eduardo. "Manifestaciones de la oralidad como sistema de expresión literaria y mítica en algunos relatos de Arguedas". Lexis 31.1-2 (2007): 177-207. Impreso.

Larco, Juan, Comp. Recopilación de textos sobre José María Arguedas. Habana: Centro de Investigaciones Literarias Casa de las Américas, 1976. Impreso.

Lienhard, Martin. "La 'andinización' del pensamiento urbano". El zorro de arriba y el zorro de abajo. Ed. Eve-Marie Fell. Madrid: Archivos, 1990. 321-32. Impreso.

- Cultura andina y forma novelesca: Zorros y danzantes en la última novela de Arguedas. Ed. William Rowe, Luis Millones, y José Cerna Bazán. Lima: Horizonte, 1990. Impreso.

Mitchell, Fergus Jr. “The Foxes in Jose Maria Arguedas' Last Novel”. Hispania 61.1 (1978): 46-56. JSTOR. Web. 21 oct. 2010.

Morote Best, Efraín. Aldeas sumergidas: Cultura popular y sociedad en los Andes. Cusco: Centro de Estudios Rurales Andinos "Bartolomé de las casa", 1988. Impreso.

Ong, Walter. Orality and Literacy, The Technologizing of the Word. Nueva York: Methuen, 1982. Impreso.

Ortega, Julio. "Los zorros de Arguedas: Migraciones y fundaciones de la modernidad andina". Zorros a fin del milenio: Actas y ensayos del Seminario sobre la última novela de José María Arguedas. Ed. Wilfredo Kapsoli. Lima: Universidad Ricardo Palma, 2004. 259-81. Impreso.

Ortiz Rescaniere, Alejandro. Huarochirí, cuatrocientos años después. Lima: Pontificia Universidad Católica del Perú, 1980. Impreso.

Paz, Octavio. El arco y la lira: El poema, la revelación poética, poesía e historia, México: Fondo de Cultura Económica, 1996. Impreso.

Platt, Tristan. "Symétries en miroir le concept de yanantin chez les Macha de Bolivie". Annales histoire, sciences sociales, anthropologie historique des sociétés andines 33.5-6 (1978): 1081-107. JSTOR. Web. 10 jun. 2011.

Ratto, Luis Alberto. "Arguedas o el creador visceral". Recopilación de textos sobre José María Arguedas. Ed. Juan Larco. Habana: Centro de Investigaciones Literarias Casa de las Américas, 1976. Impreso. 
Rowe, William. Mito e ideología en la obra de José María Arguedas. Lima: Instituto Nacional de Cultura, 1979. Impreso.

Salomon, Frank. "How the Huacas were: The Language of Substance and Transformation in the Huarochiri Quechua Manuscript". Anthropology and Aesthetics: Pre-Columbian States of Being 33 (1998): 7-17. JSTOR. Web. 18 mar. 2012.

Stern, Alfred. Filosofía de la risa y el llanto. Trad. Julio Cortázar. Buenos Aires: Imán, 1950. Impreso.

Uhle, Max, Comp. El cóndor y el zorro. Ed. Wilfredo Kapsoli. Lima: Universidad Ricardo Palma, 2003. Impreso.

Urioste, George L. Hijos de Pariya Qaqa: La tradición oral de Waru Chiri (Mitología, Ritual y Costumbres). Ed. y Trad. George L. Urioste. 2 vols. Nueva York: Foreign and Comparative Studies Program, 1983. Impreso.

Vargas-Salgado, Carlos. "José María Arguedas: memoria y teatralidad en los Andes". Revista de crítica literaria latinoamericana 39.77 (2013): 303-24. Impreso.

Westphalen, Emilio Adolfo. "Del mito al testimonio: La larga marcha del Perú". Recopilación de textos sobre José María Arguedas. Ed. Juan Larco. Habana: Centro de investigaciones literarias Casa de las Américas, 1976. 301-10. Impreso. 